\title{
Correction to: Coping during COVID-19: a mixed methods study of older cancer survivors
}

\author{
Jacqueline Galica ${ }^{1,2} \cdot$ Ziwei Liu $^{1}$ • Danielle Kain ${ }^{3} \cdot$ Shaila Merchant ${ }^{4} \cdot$ Christopher Booth $^{2,5,6} \cdot$ Rachel Koven $^{2}$. \\ Michael Brundage ${ }^{2,5,6,7} \cdot$ Kristen R. Haase $^{8}$
}

Published online: 22 January 2021

(C) Springer-Verlag GmbH Germany, part of Springer Nature 2021

\section{Correction to: Supportive Care in Cancer https://doi.org/10.1007/s00520-020-05929-5}

The name of Shaila Merchant was incorrectly captured in the original manuscript.

The original article has been corrected.

Publisher's note Springer Nature remains neutral with regard to jurisdictional claims in published maps and institutional affiliations.

The online version of the original article can be found at https://doi.org/ 10.1007/s00520-020-05929-5

Jacqueline Galica

jacqueline.galica@queensu.ca

School of Nursing, Queen's University, Kingston, Canada

2 Division of Cancer Care \& Epidemiology, Queen's Cancer Research Institute, Kingston, Canada

3 Division of Palliative Medicine, Departments of Medicine and Oncology, School of Medicine, Queen's University,

Kingston, Canada
4 Division of General Surgery and Surgical Oncology, Queen's University, Kingston, Canada

5 Cancer Centre of Southeastern Ontario, Kingston, Canada

6 Department of Oncology, School of Medicine, Queen's University, Kingston, Canada

7 Department of Public Health Sciences, School of Medicine, Queen's University, Kingston, Canada

8 School of Nursing, Faculty of Applied Science, The University of British Columbia, Vancouver, Canada 